\title{
Encapsulation of flaxseed oil extract in alginate-salep system by ionic gelation
}

\author{
Zam Wissam ${ }^{\circledR *}$, Housheh Samer $^{2}$ \\ ${ }^{1}$ Department of Analytical and Food Chemistry, Faculty of Pharmacy, Al-Andalus University for Medical University, Tartous, \\ Syrian Arab Republic, ${ }^{2}$ Department of Pharmaceutical Chemistry and Quality control, Faculty of Pharmacy, Al-Andalus \\ University for Medical University, Tartous, Syrian Arab Republic
}

\begin{abstract}
The objective of the current study was to encapsulate flaxseed oil extracted from finely grounded flaxseed powder and determined for its fatty acids content by GC/FID. Ionotropic gelation method was used to form beads containing $40 \%$ flaxseed oil with vitamin $\mathrm{E}$ being used as an antioxidant agent. The study employed calcium chloride solution as crosslinking agent with a combination of sodium alginate and salep. The effect of polymer concentrations and calcium chloride concentration on the morphology, entrapment efficiency and oil release was studied. The encapsulation efficiency reached $93.46 \pm 0.064 \%$ using $0.6 \%$ of salep and $2 \%$ sodium alginate with $0.3 \mathrm{M}$ calcium chloride gelling solution. In SGF medium, the matrix released only about $28.56 \%$ of the entrapped flaxseed oil after 2 hours. The rest of the oil then released in the SIF medium, continuing for up to $5 \mathrm{~h}$ to release $99.32 \%$ of the oil.
\end{abstract}

Keywords: Flaxseed oil. Sodium alginate. Salep. Beads.

\section{INTRODUCTION}

Flaxseed is emerging as an important food ingredient because of its rich contents of $\omega-3$ fatty acid specially $\alpha$-linolenic acid (Tonon, Grosso, Hubinger, 2011), phytoestrogens such as lignans, and soluble dietary fiber (Martinchik et al., 2012). In the last two decades, flaxseed has been the focus of increased interest in the field of diet and disease research due to the potential health benefits associated with some of its biologically active components. The health benefits of all $\omega-3$ fatty acids including ALA have been widely reported for several conditions including cardiovascular disease, diabetes, cancer particularly of the mammary and prostate gland, autoimmune diseases and neurological disorders (Gogus, Smith, 2010). Flaxseed has been reported to act as anti-arrhythmic (Ander et al., 2004), anti-atherosclerosis (Prasad, 2009), and antiinflammatory (Dupasquier et al., 2007) agent in addition to improving vascular function (Dupasquier et al., 2006).

With the increasing rate of chronic diseases in societies, flax products are increasingly used as functional foods and nutraceuticals. Flaxseeds can be

\footnotetext{
*Correspondence: W. Zam. Al-Andalus University for Medical Sciences, Faculty of Pharmacy, Analytical and Food Chemistry, Tartous, Syrian Arab Republic. Tel: +932933724703. E-mail: w.zam@au.edu.sy
}

used as roasted and milled seeds, while flaxseed oil can be used in various food formulations (Goyal et al., 2014). One of the major problems associated with oils rich in polyunsaturated fatty acids is their high susceptibility to oxidative deterioration and consequent production of undesirable flavor. Thus, there is a need to protect these oils in order to make them more stable during handling, processing and storage (Augustin, Sanguansri, Bode, 2006). Ionotropic gelation technique $\mathrm{g}$ is a process widely used for microencapsulation and has gained great attention recently (Patil et al., 2010). Through this technique, beads are formed when ionic polymer such as sodium alginate, chitosan and konjac glucomannan undergo ionotropic gelation and precipitate due to electrostatic interaction between oppositely charged species. This is a very simple technique, non-toxic and easy to control in terms of production.

Sodium alginate is one of the most common wall materials used in microencapsulation by ionotropic gelation. It is a water soluble salt of a naturally occurring copolymer of guluronic and manuronic acids (Wang, $\mathrm{He}$ 2002). Alginate has a unique gel-forming property in the presence of multivalent cations, such as calcium ions, which takes place mainly at junctions in the G-G sequence rich chain region (Xing et al., 2003). 
Salep is a hydrocolloid powder obtained from dried roots/tubers of Orchis morio, from the Orchidaceae family (Karaman, Kayacier 2010). The main polysaccharide content of palmate tubers of salep extracts is glucomannan (Tang et al., 2002). Glucomannans consist of D-glycopyranosyl and D-mannopyranosyl residues at a ratio of $1: 3.3$, its backbone chain consisting of $b(1 \rightarrow 4)$ linked glycosyl and mannosyl residues (Georgiadis et al., 2012). Razavi et al. (2014) has used salep as a novel polymer to develop hydrophilic, gastroretentive matrix tablets of famotidine with good floating and swelling properties.

Very little information is available on microencapsulation of flaxseed oil (Partanen et al., 2008; Omar et al., 2009; Tonon, Grosso, Hubinger, 2011; Carneiro et al., 2013) and none of the published works reported the use of salep as a new polymer for encapsulation, also any of the previous researches deals with the influence of different types of wall materials on the encapsulation efficiency and oxidative stability of this oil.

Based on the similarity in chemical structure of both salep and konjac glucomannan, a linear random copolymer of $\beta$ - $(1 \rightarrow 4)$ linking D-mannose and D-glucose (Mohamed et al., 2015), we investigated the use of salep as a new polymer for microencapsulation by ionic gelation in combination with sodium alginate. The emulsions were characterized for stability, while the microcapsules were characterized for encapsulation efficiency, morphology, oxidative stability and in-vitro release.

\section{MATERIAL AND METHODS}

\section{Material}

Sodium alginate powder, polyoxyethylene sorbitan monooleate (Tween 80), sorbitan monolaurate (Span 60 ) and DL- $\alpha$-Tocopherol acetate tested according to $\mathrm{Ph}$.Eur. were obtained from Sigma-Aldrich Co, St. Louis, MO, USA. Food brand orchid extract powder (salep) was purchased from Kahramanmaras, Turkey. All other chemicals are of analytical reagent (AR) grade.

\section{Extraction of oil from flaxseed}

$100 \mathrm{~g}$ of finely grounded flaxseed powder was mixed with $1000 \mathrm{~mL} n$-hexane and extracted according to the method described by Gutte et al. with slight modifications. The sample was extracted under continuous ultrasonic waves at $30^{\circ} \mathrm{C}$ for $40 \mathrm{~min}$. It was followed by the addition of $1000 \mathrm{~mL}$ dichloromethane and the mixture was kept at room temperature for $24 \mathrm{~h}$. It was then filtered using a vacuum filtration to remove suspended solids. Subsequently, the solvent was evaporated from the oil using rotary vacuum evaporator and extracted oil was collected in the receiving flask (Gutte, Sahoo, Ranveer, 2015).

\section{Gas chromatographic analysis}

Fatty acid compositions of the oils extracted were determined by Gas Chromatography (GC). The oil samples obtained were esterified according to the AOAC (2000) method and injected into the chromatograph (AOAC, 2000). Chromatography was performed with SHIMADZU GC 2010 system equipped with a flameionization detector and a $30 \mathrm{~m} \times 0.25 \mathrm{~mm}$ i.d. column coated with a $0.25 \mu \mathrm{m}$ film of HP-23. Split injection (split ratio 1:50) was performed, with hydrogen as carrier gas at a flow rate of $40 \mathrm{~m} \cdot \mathrm{s}^{-1}$. The column temperature was maintained at $160{ }^{\circ} \mathrm{C}$ for 1 min after injection then programmed at $2.5^{\circ} \mathrm{min}^{-1}$ to $215^{\circ} \mathrm{C}$, which was held for $2 \mathrm{~min}$, and then at $40^{\circ} \mathrm{min}^{-1}$ to $230^{\circ} \mathrm{C}$, which was held for $2 \mathrm{~min}$. The injection port and detector temperatures were $270{ }^{\circ} \mathrm{C}$.

\section{Preparation of alginate/salep-oil emulsion}

An emulsion was prepared using $40 \mathrm{~mL}$ of flaxseed oil extract fortified using vitamin E $(200 \mathrm{mg} / 100 \mathrm{~g})$ and $60 \mathrm{~mL}$ of distilled water. $2 \mathrm{~mL}$ of Tween 80 and Span 60 mixture (7:3) was used for emulsification at a speed of $300 \mathrm{rpm}$ for $45 \mathrm{~min}$.

A mixture of sodium alginate $(1,2,3 \% \mathrm{w} / \mathrm{v})$ and salep $(0.2,0.4,0.6,0.8 \% \mathrm{w} / \mathrm{v})$ were allowed to dissolve in the prepared emulsion.

\section{Determination of emulsion stability (ES)}

Fifty milliliters of alginate/salep-oil emulsion was left standing for $12 \mathrm{~h}$ at room temperature to determine the extent of phase separation, if any. The density of flaxseed oil was found to be lower than that of the alginate/salep solution, and therefore the oil droplets had a tendency to move upward, which is described as creaming (Huang, Kakuda, Cui, 2001). The volume of the upper phase measured after $12 \mathrm{~h}$ and the stability was measured by $\%$ of separation and expressed as:

$$
\text { Separation }(\%)=\left(\frac{\mathrm{H}_{1}}{\mathrm{H}_{0}}\right) * 100
$$

where: $\mathrm{H}_{0}$ represents the emulsion initial height and $\mathrm{H}_{1}$ is the upper phase height. 


\section{Bead formation}

Approximately $5 \mathrm{~mL}$ of alginate/salep-flaxseed oil emulsion was extruded through a $0.55 \mathrm{~mm}$ needle and dripped into $50 \mathrm{~mL}$ of calcium chloride gelling solution $(0.2,0.3,0.4 \mathrm{M})$ to form oil-loaded, Ca-alginate/salep beads. The tip of the needle was fixed at $15 \mathrm{~cm}$ above the surface of the gelling bath. Capsules were hardened in $\mathrm{CaCl}_{2}$ solution for $30 \mathrm{~min}$, and then was filtered and rinsed with distilled water. The rinsed capsules were allowed to dry in air at room temperature until constant weight could be achieved.

\section{Determination of encapsulation efficiency (\%)}

Encapsulation efficiency (\%) was determined according to the method described by Bae and Lee with slight modifications (Bae, Lee, 2008). Fifteen milliliters of hexane were added to dried beads formed using $5 \mathrm{~mL}$ of alginate/salep-flaxseed oil emulsion, followed by stirring for $15 \mathrm{~min}$ at room temperature. Then, the solvent was evaporated using rotary vacuum evaporator and oil was collected in the receiving flask for GC/FID analysis. The encapsulation efficiency (\%) of all the calcium alginate beads containing $40 \%$ flaxseed oil was calculated based on alpha-linolenic acid (ALA, C18:3).

\section{Oxidative stability}

Beads were sealed in a glass vial $(20 \mathrm{~mL})$, stored at $45{ }^{\circ} \mathrm{C}$ in order to accelerate the oxidation process, and evaluated for oxidation by peroxide value right after drying and over four weeks of storage. Hydroperoxide concentrations were determined using a $\mathrm{Fe}^{+3}$ standard curve with iron concentration varying from 1 to $24 \mu \mathrm{g}$ (Shantha, Decker, 1994).

\section{In vitro release studies}

In-vitro release studies were carried out using the USP-II dissolution test apparatus (Copley Scientific Limited, Nottingham, UK).

Dissolution medium of $900 \mathrm{~mL}$ of simulated gastric fluids, SGF (0.1 M HCl, $\mathrm{pH} 1.2)$, was used in the dissolution basket and maintained at a temperature of $37^{\circ} \mathrm{C} \pm 0.5^{\circ} \mathrm{C}$ for 2 hours. Then, the dissolution medium was replaced by simulated intestinal fluid, SIF (phosphate buffer, $\mathrm{pH}$ 7.4) and held until the beads were disintegrated. Paddle speed was maintained at $50 \mathrm{rpm}$ and $5 \mathrm{~mL}$ samples were withdrawn at predetermined time intervals, and $5 \mathrm{~mL}$ of the fresh medium, kept at the same temperature, was replaced. The samples were extracted using hexane and analyzed by GC/FID to determine the flaxseed oil release. The dissolution profile was obtained by plotting the cumulative percentage of flaxseed oil released on the $\mathrm{y}$-axis and time (in hours) on the $\mathrm{x}$-axis (Razavi et al., 2014).

\section{RESULTS AND DISCUSSION}

\section{Fatty acid composition as measured through GC-FID}

The identification of the peaks was achieved by retention times by means of comparing them with standards analyzed under the same conditions. The area under each peak was measured and the percentage expressed in regard to the total area. GC analyses combined with NIST 05 database searches confirmed the identification of fatty acid methyl esters across extraction techniques, thereby confirming quantitative measures. Figure 1 shows the main fatty acids found in flaxseed oil extract. Palmitic acid (C16:0), stearic acid (C18:0), oleic acid (C18:1), linoleic acid (LA, C18:2) and alpha-linolenic acid (ALA, C18:3) were the major FAs identified by GC-FID.

The fatty acid compositions of flaxseed oil extracted by ultrasonic assisted extraction are given in Table I. The fatty acid recorded in ultrasonic assisted extraction methods were saturated fatty acids $(12.16 \%)$, monounsaturated fatty acids $(20.37 \%)$ and polyunsaturated fatty acids $(66.53 \%)$, respectively.

\section{Stability of alginate/salep emulsion}

As reported by Klaypradit and Huang (2008) the emulsion stability has a significant influence on the encapsulation efficiency. Hosseini et al. (2015) indicated that small droplets and stable emulsion of flaxseed oil could be achieved using a mixture of Tween 80 and Span 60 with the HLB of 11.7. Therefore, a mixture of Tween 80 and Span 60 (7:3) were used for emulsification.

Prior to the encapsulation process, the alginate/ salep-flaxseed oil emulsion was left standing for $12 \mathrm{~h}$ to determine the extent of phase separation, if any. Duration of $12 \mathrm{~h}$ was used because the time-frame for the encapsulation process for a batch couldn't exceed this time. The concentrations of alginate and alginate/salep mixture used ranged from 1 to 3 and 2.2 to $2.8(\% \mathrm{w} / \mathrm{v})$, respectively. Higher concentrations were not attempted because they were difficult to process due to their high viscosities. The effect of alginate and alginate/salep concentration on the ES is shown in Figure 2. 
TABLE I - Fatty acid composition ( $\%$ of total fatty acids) of flaxseed oil extract

\begin{tabular}{lc}
\hline Fatty acid & (\% of total fatty acids) \\
\hline \multicolumn{3}{c}{ Saturated Fat } \\
\hline C 16:0 & 6.71 \\
C 18:0 & 5.45 \\
Total saturated fats & 12.16 \\
\hline \multicolumn{3}{c}{ Monounsaturated Fats } \\
\hline C 18:1 n-9 & 20.37 \\
Total monounsaturated fats & 20.37 \\
\hline \multicolumn{3}{c}{ Polyunsaturated fats } \\
\hline C 18:2 n-6 \\
C 18:3 n-3 14.21 \\
Total polyunsaturated fats & 52.32 \\
\hline
\end{tabular}

The ES was found to increase with higher alginate concentration ranging from $95.56 \%$ for the alginate $1 \%(\mathrm{w} / \mathrm{v})$ to $98.26 \%$ for the alginate $2 \%(\mathrm{w} / \mathrm{v})$. The emulsion was found to be stable, and no phase separation was observed when the alginate concentration was 3\% (w/v) and higher. The addition of salep to the emulsion mixture increased the emulsion stability as it increased the viscosity. The addition of $0.2 \mathrm{~g} / 100 \mathrm{~mL}$ of salep to the emulsion prepared using $1 \mathrm{~g} / 100 \mathrm{~mL}$ alginate increased the stability of the emulsion from $98.26 \%$ to $99.75 \%$ and no phase separation was observed when the concentration of the alginate:salep mixture was 2:0.4\% (w/v) and higher.

Our results were in accordance with Ong et al. (2015), who reported that the size distribution of refined palm oil droplets was narrow and monomodal when emulsified using $2 \%(\mathrm{w} / \mathrm{v})$ of alginate and $1 \%(\mathrm{w} / \mathrm{v})$ of surfactants, even at an oil loading of $70 \%(\mathrm{v} / \mathrm{v})$. The emulsions formed were found to be stable against phase separation. Chan also studied the effect of alginate concentration on the ES of palm oil. The ES was found to increase with no phase separation observed when the alginate concentration was $2.5 \%(\mathrm{w} / \mathrm{v})$ and higher (Chan, 2011).

The increase of alginate-salep concentration resulted in an increase in the viscosity of the continuous phase, thereby causing more restriction to the movement of oil droplets and more time for surfactants adsorption, thus reducing the tendency for droplets coalescence. In addition, alginate as a hydrophilic polysaccharide hydrocolloid is expected to have a low surface activity (Chan, 2011). This could explain improved emulsion stability with the increase of alginate-salep concentration. However, at low alginate-salep concentration, the oil droplets could be more mobile and this could promote droplets coalescence and phase separation.

\section{Flaxseed oil encapsulation efficiency (\%)}

By using the extrusion-dripping technique, a liquid

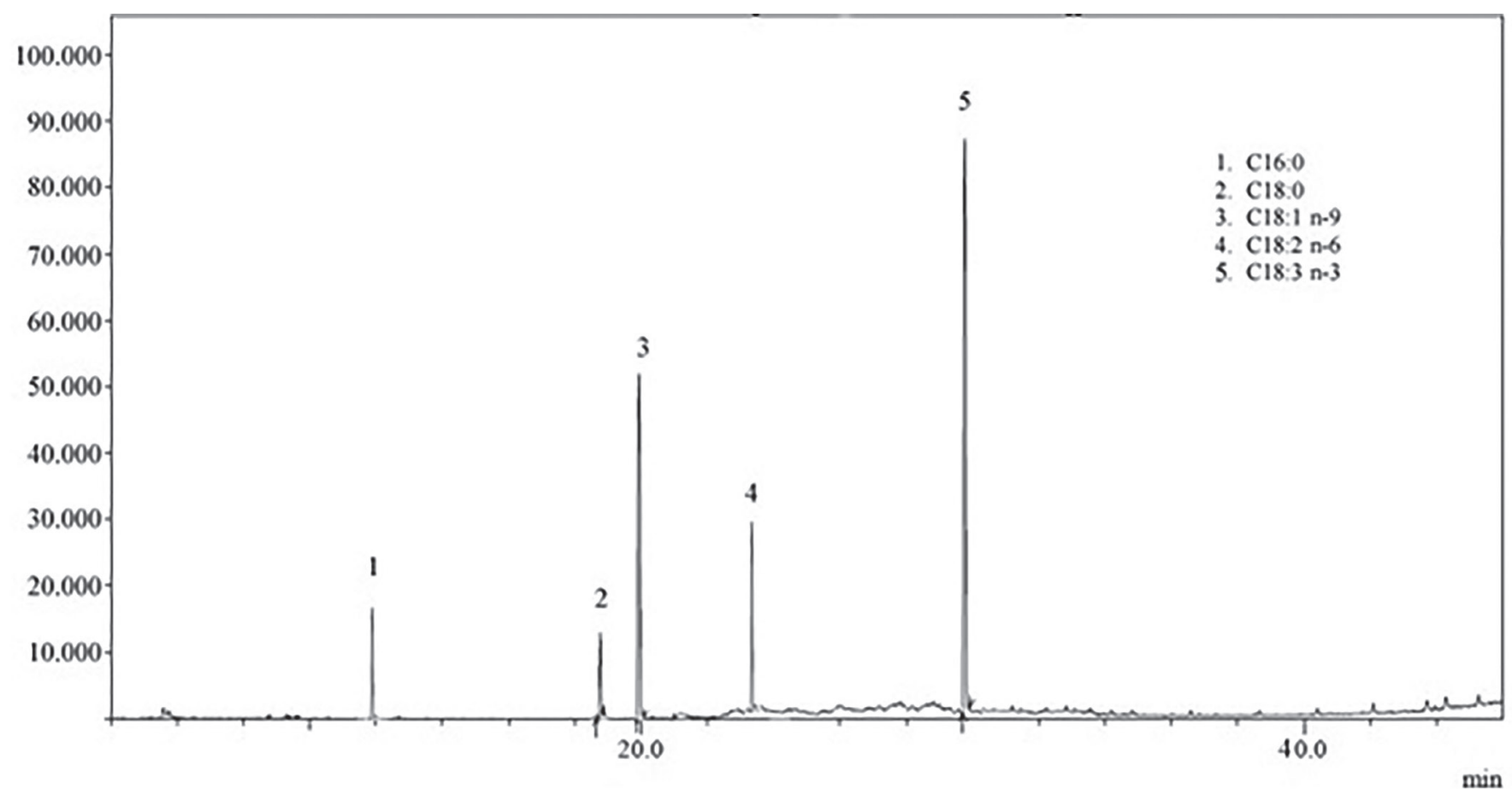

FIGURE 1 - GC-FID chromatogram of main methyl esters of fatty acids palmitic acid (1), stearic acid (2), oleic acid (3), linoleic acid (4) and alpha-linolenic acid (5) from flaxseed oil extract. 


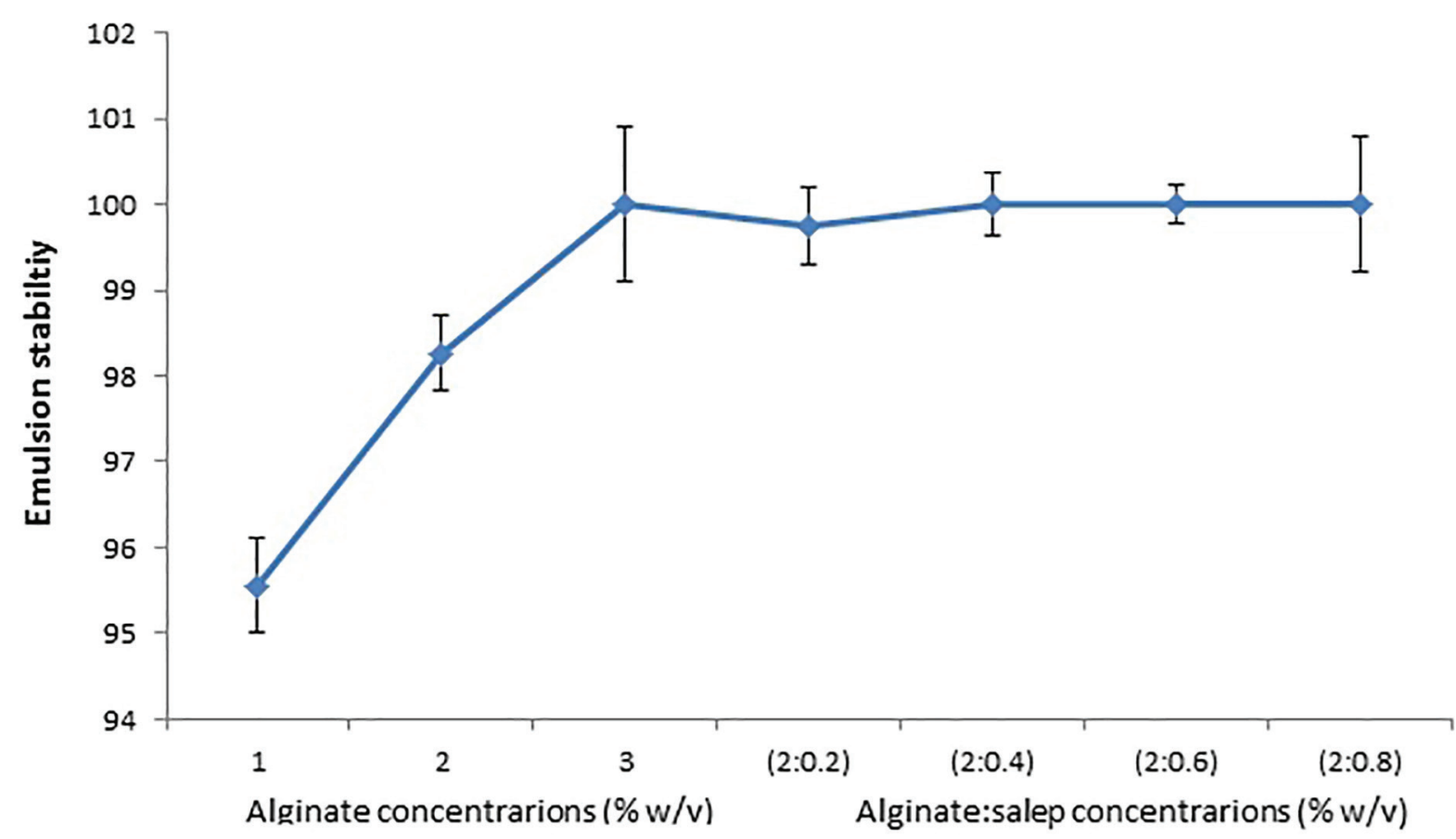

FIGURE 2 - Effect of alginate-salep concentrations on the Stability of alginate/salep-flaxseed oil emulsion (oil loading 40\%).

pendant droplet grows at the capillary tip until the surface tension force no longer supports the weight of the droplet. At this instant, the liquid droplet detaches from the tip and falls into the gelling bath to form a bead. The concentration of sodium alginate used for entrapment also affects the shape of beads and so the loading efficiency. At alginate concentration of 1 and $2(\% \mathrm{w} / \mathrm{v})$, the beads produced were spherical as shown in Figure 3. For alginate solution of higher concentration $3(\% \mathrm{w} / \mathrm{v})$, distinct tailed beads were formed. This is in accordance to previous researchers which found that alginate concentration of 1.5-2.5 (5 w/v)

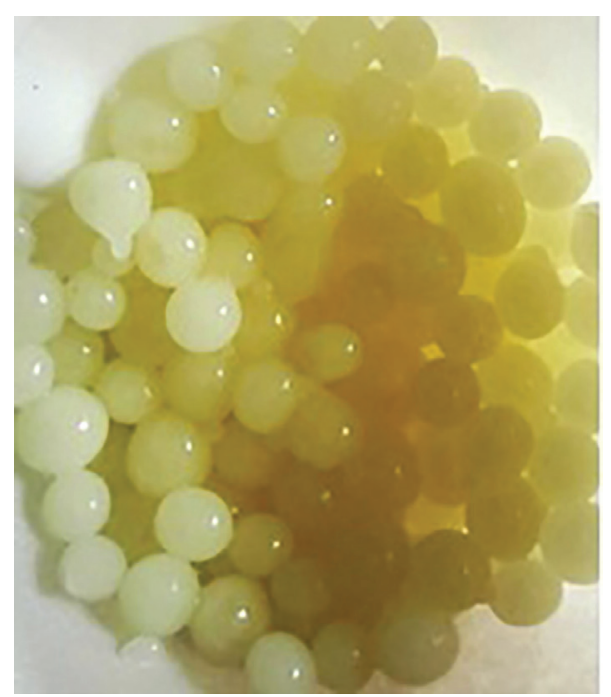

FIGURE 3 - Photograph of the spherical calcium alginate/salep beads of flaxseed oil extract. was the optimal concentration range to form spherical beads even at high oil loading up to $50 \mathrm{vol} \%$ (Chan et al., 2009; Chan, 2011).

The encapsulation efficiency ( $\%$ ) of all the calcium alginate beads containing $40 \%$ flaxseed oil was within the range $43.89 \pm 0.057$ to $59.78 \pm 0.045 \%$ (Table I). As noticed, higher loading efficiency was obtained as the concentration of alginate increased. This may be attributed to the greater availability of active calcium binding sites in the polymeric chains and consequently, the greater degree of crosslinking as the quantity of sodium alginate increased (Zam et al., 2014).

Previous studies had proved that more effective beads for the compounds entrapment can be formed by using a combination of both alginate and another polymer such as pectin or chitosan (Bhattarai, Dhandapani, Shrestha, 2011; Jaiswal et al., 2009; Zam et al., 2013).

Salep is a hydrocolloid powder obtained from dried roots/tubers of Orchis morio var mascula, from the Orchidaceae family (Karaman, Kayacier, 2010). Currently, it is used as a gelling agent, thickening agent, and stabilizer in ice cream production, since it swells when in contact with water or milk, as well as for its pleasant aroma, smell, and taste (Kaya, Tekin, 2001). The main polysaccharide content salep is glucomannan (Tang et al., 2002) which consists of D-glycopyranosyl and D-mannopyranosyl residues at a ratio of 1:3.3, its backbone chain consisting of $\mathrm{b}(1 \rightarrow 4)$ linked glycosyl and mannosyl residues (Georgiadis et al., 2012). Therefore, 
it has the same structure as konjac glucomannan which is a heteropolysaccharide consisting of D-mannose and D-glucose in a ratio of $1.6: 1$ with $b(1,4)$ linkages (Thomas, 1997). konjac glucomannan was used with sodium alginate for the encapsulation of bovine serum albumin and this combination gave better loading efficiency as it increases the viscosity of the polymer solution and so drug leaching during beads preparation might be prevented (Mohamed et al., 2015).

Salep was used as a novel polymer to prepare floating, gastroretentive matrix tablets of famotidine in order to improve release of drugs in the stomach and upper gastrointestinal tract (Razavi et al., 2014).

Based on these results, salep was used in combination with sodium alginate to improve the loading efficiency of flaxseed oil. As presented in Table II, the addition of $0.2 \%$ of salep to $2 \%$ sodium alginate increases the loading efficiency from $58.91 \pm 0.068$ to $85.78 \pm 0.035 \%$, and the best entrapment efficiency of $92.34 \pm 0.013 \%$ was obtained using a combination of $0.8 \%$ salep and $2 \%$ sodium alginate. However, tailed beads were formed using this combination and so the mixture of $0.6 \%$ salep and $2 \%$ sodium alginate with a loading efficiency of $91.65 \pm 0.029 \%$ was used for further experiments as the beads produced were spherical.

Polyvalent cations such as calcium bind to the polymer whenever there are two neighboring guluronic acid residues. Thus the polyvalent cations are responsible for the cross-linking of both different polymer molecules and different parts of the same polymer chain. Results presented in Table II showed that different concentrations of Calcium chloride $(0.2,0.3,0.4 \mathrm{M})$ had significant influence on flaxseed oil loading $(p>0.05)$. Loading efficiency increased as the concentration of calcium chloride increased from 0.2 to $0.3 \mathrm{M}$, which can be explained by the increase in the gel strength (Zam et al., 2014). However, the loading efficiency decreased at concentration of calcium chloride $0.4 \mathrm{M}$, which may be due to osmotic stress as reported by Takayuki et al. (2009).

Peroxide value variations of flaxseed oil encapsulated with the combination of $0.6 \%$ salep and $2 \%$ sodium alginate using calcium chloride solution $(0.3 \mathrm{M})$ are shown in Figure 4. At time zero, the sample showed a low level of oxidation $3.53 \mathrm{meq}$ peroxide $/ \mathrm{kg}$ oil which reached the value of 4.03 meq peroxide $/ \mathrm{kg}$ oil after 4 weeks. Statistical analysis showed that there was no significant difference $(p<0.01)$ between the extent of oxidation in beads after 4 weeks of accelerated oxidation process whcih can be explained by the use of vitamin $\mathrm{E}$ (200 mg/100 g).

\section{In vitro release studies}

The percentage of drug release was measured for the formulation prepared by the combination of $0.6 \%$ salep and $2 \%$ sodium alginate using calcium chloride solution $(0.3 \mathrm{M})$. The release from the alginate/salep beads depends on the penetration of the dissolution medium into the beads, swelling and dissolution of alginate/salep matrix, and the diffusion of the flaxseed oil through the swollen matrix. In SGF medium, the matrix releases only about $28.56 \%$ of the entrapped flaxseed oil after 2 hours. This may be due to the stability and non-swelling property of alginate in acidic medium (Lee, Min, Cui, 1999) and the conversion of $\mathrm{Ca}$-alginate to insoluble alginic

TABLE II - Effect of formulation variables on the characteristics of alginate/salep flaxseed oil beads

\begin{tabular}{|c|c|c|c|}
\hline \multicolumn{4}{|c|}{ Formulation variables } \\
\hline $\begin{array}{c}\text { Sodium alginate } \\
\text { concentration }(w / v \%)\end{array}$ & Salep concentration $(w / v \%)$ & $\begin{array}{c}\text { Calcium chloride } \\
\text { concentratrion (M) }\end{array}$ & $\begin{array}{c}\text { Loading efficiency (\%) } \\
(\% \pm \text { sd }, n=3)\end{array}$ \\
\hline 1 & - & 0.2 & $43.89 \pm 0.057$ \\
\hline 2 & - & 0.2 & $58.91 \pm 0.068$ \\
\hline 3 & - & 0.2 & $59.78 \pm 0.045$ \\
\hline 2 & 0.2 & 0.2 & $85.78 \pm 0.035$ \\
\hline 2 & 0.4 & 0.2 & $87.47 \pm 0.094$ \\
\hline 2 & 0.6 & 0.2 & $91.65 \pm 0.029$ \\
\hline 2 & 0.8 & 0.2 & $92.34 \pm 0.013$ \\
\hline 2 & 0.6 & 0.2 & $91.65 \pm 0.029$ \\
\hline 2 & 0.6 & 0.3 & $93.46 \pm 0.064$ \\
\hline 2 & 0.6 & 0.4 & $87.56 \pm 0.076$ \\
\hline
\end{tabular}




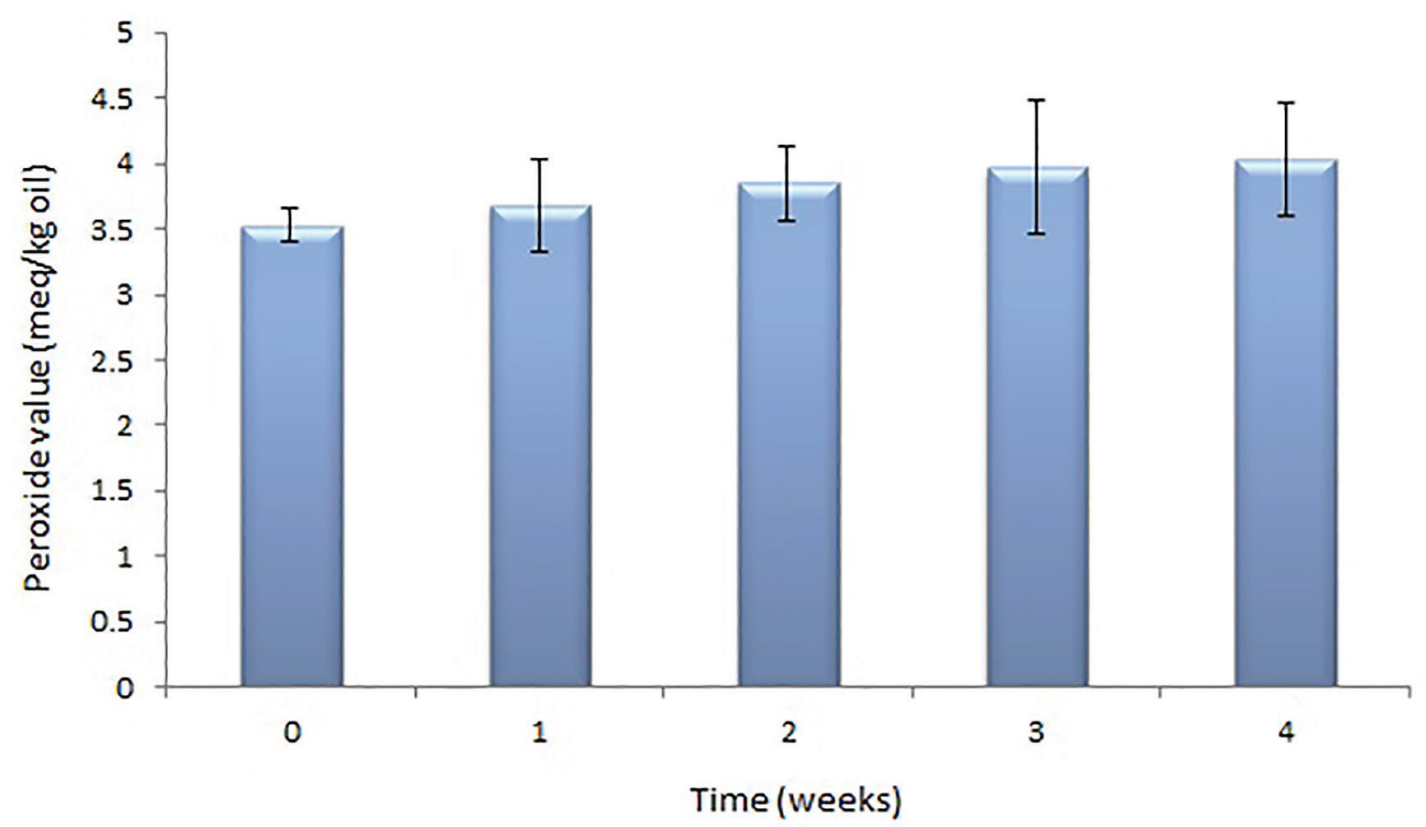

FIGURE 4 - Oxidative stability of encapsulated flaxseed oil evaluated by peroxide value method.

acid (Hodson et al., 1995). The salep film also forms an additional adhesive, thick and viscous barrier, which decreases the amount of water penetrating into the deeper layers of the matrix. The rest of the oil then releases in the SIF medium, continuing for up to $5 \mathrm{~h}$ to release $99.32 \%$ of the oil as shown in Figure 5.

The release of flaxseed oil in simulated intestinal fluids can be explained on the basis of swelling and erosion. In phosphate buffer the rapid swelling created porous structure and brought more liquid inside the beads (El-Gindy, 2002). Moreover, ion exchange with phosphate buffer and formation of the solute alginate led to erosion of the beads (Turkoglu et al., 1997). Razavi et al. (2014) had shown in a previous research that salep had a lower viscosity at $\mathrm{pH} 7.4$ compared with its viscosity at $\mathrm{pH} 1.2$ which could give an additional explanation for the rapid distruction of the beads.

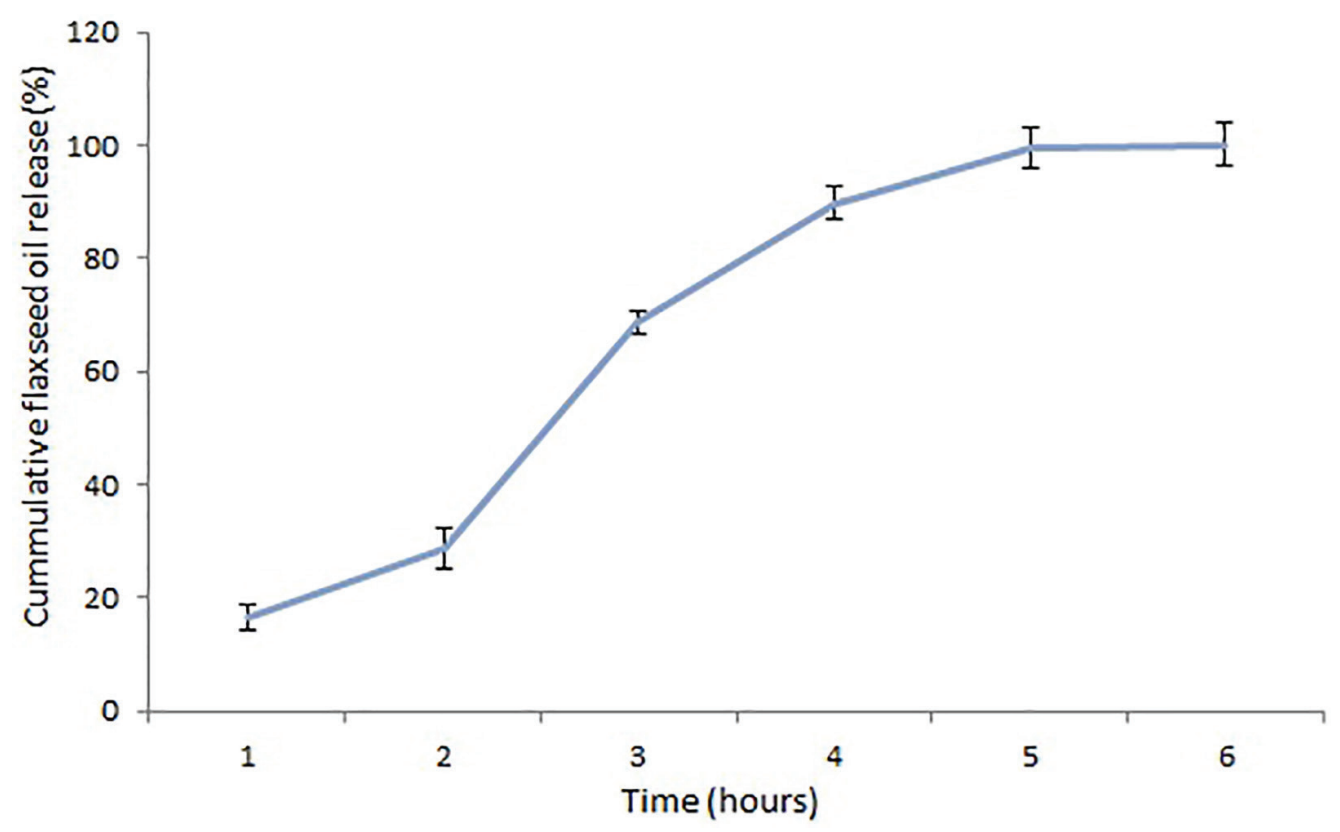

FIGURE 5 - Flaxseed oil release profile of calcium alginate/salep beads in 6-hours in vitro study. SGF (0.1 M HCl, pH 1.2), was maintained at a temperature of $37^{\circ} \mathrm{C} \pm 0.5^{\circ} \mathrm{C}$ for 2 hours. Then, the dissolution medium was replaced by SIF (phosphate buffer, $\mathrm{pH}$ 7.4) and held until the beads were disintegrated. 


\section{CONCLUSION}

The present research proposed a novel formulation to encapsulate flaxseed oil extracted from finely grounded flaxseed powder. Salep, a new hydrogel and swellable polymer, was used in combination with sodium alginate by the ionotropic gelation method, using calcium chloride as a crosslinking agent. Different formulations, with various ratios of salep and sodium alginate as hydrogel, were evaluated and optimized. Investigation of the preparation, characterisation, and in vitro release of the encapsulated flaxseed oil was carried out. According to the studied factors, the selected optimum formulation was that prepared with $2 \%(\mathrm{w} / \mathrm{v})$ of sodium alginate and $0.6 \%(\mathrm{w} / \mathrm{v})$ of salep gelled using $0.3 \mathrm{M}$ calcium chloride solution. Only $28.56 \%$ of flaxseed oil released during treatment with $0.1 \mathrm{M} \mathrm{HCl}$ for $2 \mathrm{~h}$; however, the beads released almost all the entrapped flaxseed oil into phosphate buffer $\mathrm{pH} 6.8$ media within $5 \mathrm{~h}$.

\section{REFERENCES}

Ander BP, Weber AR, Rampersad PP, Gilchrist JS, Pierce GN, Lukas A. Dietary flaxseed protects against ventricular fibrillation induced by ischemia-reperfusion in normal and hypercholesterolemic Rabbits J Nutr. 2004;134(12):3250-6.

AOAC. AOAC method 963.22. Methyl esters of fatty acids in oils and fats. Official methods of analysis of the AOAC, 17th edn., AOAC, Arlington, Virginia USA; 2000.

Augustin MA, Sanguansri L, Bode O. Maillard reaction products as encapsulants for fish oil powders. J Food Sci. 2006;71(2):2532.

Bae EK, Lee SJ. Microencapsulation of avocado oil by spray drying using whey protein and maltodextrin. J Microencapsulation. 2008;25(8):549-560.

Bhattarai RS, Dhandapani NV, Shrestha A. Drug delivery using alginate and chitosan beads: An Overview. Chron Young Sci. 2011;2(4):192-6.

Carneiro HCF, Tonon RV, Grosso CRF, Hubinger MD. Encapsulation efficiency and oxidative stability of flaxseed oil microencapsulated by spray drying using different combinations of wall materials. J Food Eng. 2013;115(4):443-51.

Chan ES, Lee BB, Ravindra P, Poncelet D. Prediction models for shape and size of calcium-alginatemacrobeads produced through extrusion technique. J Colloid Interface Sci. 2009;338(1):63-72.
Chan ES. Preparation of Ca-alginate beads containing high oil content: Influence of process variables on encapsulation efficiency and bead properties. Carbohydrate Polymers. 2011;84(4):1267-75.

Dupasquier CM, Weber AM, Ander BP, Rampersad PP, Steigerwald S, Wigle JT et al. Effects of dietary flaxseed on vascular contractile function and atherosclerosis during prolonged hypercholesterolemia in rabbits. Am J Physiol Heart Circ Physiol. 2006;291(6):H2987-96.

Dupasquier CM, Dibrov E, Kneesh AL, Cheung PK, Lee KG, Alexander HK et al. Dietary flaxseed inhibits atherosclerosis in the LDL receptor-deficient mouse in part through antiproliferative and anti-inflammatory actions. Am J Physiol Heart Circ Physiol. 2007;293(4):H2394-402.

El-Gindy GA. Preparation and in-vitro evaluation of alginate beads of flurbiprofen. Bull Pharm Sci. 2002;25:229-238.

Georgiadis N, Ritzoulis C, Charchari E, Koukiotis C, Tsioptsias $\mathrm{C}$, Vasiliadou C. Isolation, characterization and emulsion stabilizing properties of polysaccharides form orchid roots (salep). Food Hydrocolloid. 2012;28(1):68-74.

Gogus U, Smith C. n-3 Omega fatty acids: a review of current knowledge. Int J Food Sci Technol. 2010;45(3):417-36.

Goyal A, Sharma V, Upadhyay N, Gill S, Sihag M. Flax and flaxseed oil: an ancient medicine \& modern functional food. J Food Sci Technol. 2014;51(9):1633-53.

Gutte KB, Sahoo AK, Ranveer RC. Effect of ultrasonic treatment on extraction and fatty acid profile of flaxseed oil. OCL. 2015;22(6):D606.

Hodson A, Mitchell J, Davies M, Melia C. Structure and behavior of hydrophilic matrix sustained release dosage form. The influence of $\mathrm{pH}$ on the sustained-release performance and internal gel structure of sodium alginate matrices. J. Control. Release. 1995;33(1):143-52.

Hosseini S, Tarzi BG, Gharachorloo M, Ghavami M, Bakhoda H. Optimization on the Stability of Linseed Oil-in-Water Nanoemulsions Generated by Ultrasonic Emulsification Using Response Surface Methodology (RSM). Orient J Chem. 2015;31(2):1223-1230.

Huang X, Kakuda Y, Cui W. Hydrocolloids in emulsions: Particle size distribution and interfacial activity. Food Hydrocolloids. 2001;15(4-6):533-42. 
Jaiswal D, Bhattacharya A, Yadav IK, Singh HP, Chandra D, Jain DA. Formulation and evaluation of oil entrapped floating alginate beads of ranitidine hydrochloride. Int J Pharm Pharm Sci. 2009;1(1):128-140.

Karaman S, Kayacier A. Rheological characteristics of traditional salep drink flavored with cocoa powder. GIDA. 2010;35(6):397.

Kaya S, Tekin AR. The effect of salep content on the rheological characteristics of a typical ice-cream mix. J Food Eng. 2001;47(1):59-62.

Klaypradit W, Huang YW. Fish oil encapsulation with chitosan using ultrasonic atomizer. LWT-Food Sci Technol. 2008;41:1133-39.

Lee GJ, Min GH, Cui JH. Correlation of drug solubility with trapping efficiency and release characteristics of alginate beads. Pharm Pharmacol Commun. 1999;5(2):85-9.

Martinchik AN, Baturin AK, Zubtsov VV, Molofeev VIU. Nutritional value and functional properties of flaxseed. Vopr Pitan. 2012;81(3):4-10.

Mohamed HN, Mustafa S, Fitrianto A, Manap YA. Optimization and characterization of calcium alginate/konjac glucomannan beads as oral protein drug delivery system. Int J Curr Pharm Clin Res. 2015;15(2):94-105.

Omar KA, Shan L, Zou X, Song Z, Wang X. Effects of two emulsifiers on yield and storage of flaxseed oil powder by response surface methodology. Pak J Nutr. 2009;8(9):1316-24.

Ong WD, Tey BT, Quek SY, Tang SY, Chan ES. Alginate-based emulsion template containing high oil loading stabilized by nonionic surfactants. J Food Scie. 2015;80(1):93-100.

Partanen R, Raula J, Seppänen R, Buchert J, Kauppinen E, Forssell P. Effect of relative humidity on oxidation of flaxseed oil in spray dried whey protein emulsions. J Agric Food Chem. 2008;56(14):5717-22.

Patil JS, Kamalapur MV, Marapur SC, Kadam DV. Ionotropic gelation and polyelectrolyte complexation: the novel techniques to design hydrogel particulate sustained modulated drug delivery system. Digest J Nanomat Biostructs. 2010;5(1):241-8.

Prasad K. Flaxseed and cardiovascular health. J Cardiovasc Pharmacol. 2009;54(5):369-77.
Razavi M, Nyamathulla S, Karimian H, Noordin MI. Novel swellable polymer of orchidaceae family for gastroretentive drug delivery of famotidine. Drug Des Devel Ther. 2014;8:131529.

Shantha NC, Decker EA. Rapid, sensitive, iron-based spectrophotometric methods for determination of peroxide value of food lipid. J AOAC Int. 1994;77(2):421-4.

Takayuki T, Masahiro Y, Yasuo H, Kouichiro S, Shiro K. Preparation of lactic acid bacteria-enclosing alginate beads in emulsion system: effect of preparation parameters on bead characteristics. Polymer Bull. 2009;63(4):599-607.

Tang OS, Schweer H, Seyberth H, Lee SW, Ho PC. Pharmacokinetics of different routes of administration of misoprostol. Hum Reprod. 2002;17(2):332-6.

Thomas WR. Konjac gum. In: A. Imeson, (Ed.), Thickening and Gelling Agents for Food. 2 nd ed. London: Blackie Academic \& Professional; 1997, p. 169-79.

Tonon RV, Grosso CRF, Hubinger MD. Influence of emulsion composition and inlet air temperature on the microencapsulation of flaxseed oil by spray drying. Food Res Int. 2011;44(1):282-9.

Turkoglu M, Gursay A, Erglu L, Okar I. Effect of aqueous polymer dispersions on properties of diclofenac / alginate beads and in vivo evaluation in rats. STP Pharm Sci. 1997;7(3):135-40.

Wang K, He Z. Alginate / konjac glucomannan/chitosan beads as controlled release matrix. Int J Pharm. 2002;244(1-2):117-26.

Xing L, Dawei C, Liping X, Rongqing Z. Oral colon-specific drug delivery for bee venom peptide, development of a coated calcium alginate gel beads-entrapped liposome. J Control Release. 2003;93(3):293-300.

Zam W, Bashour G, Abdelwahed W, Khayata W. Formulation and in-vitro release of Pomegranate peels' polyphenols microbeads. Int J Pharm Sci Res. 2013;4(9):3536-40.

Zam W, Bashour G, Abdelwahed W, Khayata W. Alginatepomegranate peels' polyphenols beads: effects of formulation parameters on loading efficiency. Braz J Pharm Sci. 2014;50(4):741-8

Received for publication on $03^{\text {rd }}$ January 2017 Accepted for publication on $22^{\text {th }}$ August 2018 